\title{
CARACTERÍSTICAS CLÍNICO-EPIDEMIOLÓGICAS DE UN BROTE DE INFLUENZA A EN PERSONAL MILITAR DE TRUJILLO, PERÚ 2008
}

\author{
Edward Chávez ${ }^{1, a}$, V. Alberto Laguna-Torres²,a,d Ana M. Burga ${ }^{3, a}$, Merly Sovero ${ }^{2, b}$, Rollin Cruz ${ }^{4, a}$, \\ Juan Pérez ${ }^{2, c}$, María Gamero $2, b$, Jane Ríos $2, b$, Tadeusz Kochel ${ }^{2, d}$
}

\begin{abstract}
RESUMEN
Se describe un brote de infección respiratoria febril aguda en una unidad militar de Trujillo, Perú. Se usó la definición de caso de síndrome gripal del Ministerio de Salud, se tomó hisopado nasal para prueba rápida de influenza (PRI) e hisopado faríngeo para aislamiento viral en cultivo celular. La genotipificación de influenza A fue por secuenciamiento genético de una región del gen de hemaglutinina teniendo como base la cepa vacunal de 2008. Se presentaron 59 casos entre el 01 y 08 de abril de 2008, la tasa de ataque fue de $82,9 \%$. La PRI identificó a 40 casos positivos de influenza A y 43 casos fueron confirmados mediante cultivo celular. Los aislamientos fueron genéticamente similares con la cepa $A$ H1N1 Brisbane. La detección precoz de un brote en lugares cerrados como las bases militares permite actuar de manera inmediata para prevenir su diseminación.
\end{abstract}

Palabras clave: Gripe humana; Brotes de enfermedades; Personal militar; Perú (fuente: DeCS BIREME).

\section{CLINICAL AND EPIDEMIOLOGICAL CHARACTERISTICS OF AN INFLUENZA OUTBREAK IN MILITARY PERSONNEL-TRUJILLO, PERU, 2008}

\begin{abstract}
We describe an acute febrile respiratory infection outbreak in a military unit in Trujillo, Peru. Cases were identified using the influenza like illness (ILI) definition of the Ministry of Health. Nasal swab samples used for a rapid influenza test (RIT) and pharyngeal swab samples for viral isolation were taken. For influenza $A$, genotyping of a partial sequence of the hemagglutinin region was performed. The rate attack was 82.9\%. Fifty-nine cases appeared between April 1 and 8, 2008; 58 came from the military unit (MU) \#1 and one from the MU \#2. The RIT identified 40 cases of influenza A and 43 cases were confirmed through cell culture. Isolations were genetically similar to the A H1N1 Brisbane strain. Early detection of outbreaks in confined locations such as military bases permits immediate action in preventing disease propagation.
\end{abstract}

Key words: Influenza, Human; Disease Outbreaks; Military Personnel; Peru (source: MeSH NLM).

\section{INTRODUCCIÓN}

La influenza es una enfermedad respiratoria aguda contagiosa que es causa importante de brotes en poblaciones militares. Esta infección puede afectar a altos porcentajes de la población militar expuesta, llegando a ocasionar $57,7 \%$ de infecciones respiratorias agudas y aproximadamente $29,6 \%$ de enfermedades gripales, inclusive ocasionando complicaciones como neumonías (entre virales y bacterianas) en $0,9 \%{ }^{(1,2)}$. También se ha descrito complicaciones tan graves como el síndrome del choque tóxico ${ }^{(3)}$ y la miositis ${ }^{(4)}$.
La enfermedad suele autolimitarse y usualmente solo se necesitan medicamentos sintomáticos, sin embargo, puede ocasionar incapacidad temporal para desarrollar las actividades cotidianas y pérdida en horas de trabajo con consecuencias económicas.

Basándose en población estadounidense del año 2003, el CDC estimó que anualmente las epidemias de influenza ocasionaron 610660 años de vida perdidos, además de un costo anual aproximado de $\$ 10,4$ billones de dólares ${ }^{(5)}$. Esto muestra la importante carga de enfermedad de esta infección y las consecuencias

\footnotetext{
Centro Médico Militar, 32. a Brigada de Infantería, Ejército del Perú. Trujillo, Perú.

2 US Naval Medical Research Center Detachment (NMRCD)-Lima. Lima, Perú.

3 Dirección de Epidemiología, Gerencia Regional de Salud La Libertad. Trujillo, Perú.

4 Jefatura de Epidemiología del Ejército, Ejército del Perú. Lima, Perú.

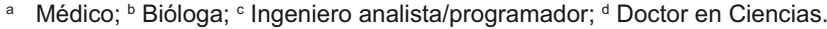


económicas que ella acarrea. Se ha demostrado, que la influenza es responsable por una intensa demanda de atención, que representa de 4 a 5 meses de tiempo en los servicios de salud de los Estados Unidos.

El Ministerio de Salud (MINSA) del Perú ha implementado un sistema de vigilancia de virus respiratorios con la participación de la Dirección General de Epidemiología (DGE), el Instituto Nacional de Salud (INS) y se ha invitado al Centro de Investigación de Enfermedades Tropicales (NMRCD) a fin de incrementar la cobertura del sistema y, además, coordinar la participación de sedes militares ${ }^{(6,7)}$. Este sistema ha permitido detectar brotes de enfermedad respiratoria en entidades militares y es así que en el año 2007 se atendió un brote de influenza B en Tumbes, en bases militares del norte del país ${ }^{(8)}$.

En el año 2006, como parte del sistema de vigilancia antes mencionado y en coordinación con la Jefatura de Salud del Ejército del Perú (JESAL), el NMRCD ha iniciado el fortalecimiento del sistema de vigilancia epidemiológica instalando centros centinela de vigilancia de influenza y otros virus respiratorios en diferentes sedes del país.

En la ciudad de Trujillo, Región La Libertad existe una Gran Unidad de Infantería (GUI) que cuenta con un Centro Médico Militar (CMM), el cual brinda atención en consultorios externos y hospitalización a todos los efectivos de esta GUI, que desde el 2008 forma parte de las unidades militares centinela del sistema de vigilancia, al igual que los centros médicos militares de Arequipa, El Rímac y Sullana.

La GUI, concentra un gran número de efectivos los cuales se distribuyen en diferentes unidades. Estas muchas veces comparten instalaciones en un mismo cuartel. Las cuadras son los espacios físicos donde el personal militar pernocta y usualmente más de una cuadra pertenece a una unidad del ejército, dependiendo del número de efectivos que tiene. En una de estas cuadras se acantonaba la Unidad Militar \#1 que en el momento del inicio del brote contaba con 70 efectivos dentro de la cuadra.

Debemos resaltar que antes del año 2008 no existía evidencia accesible que demostrara la circulación del virus de influenza en la Región La Libertad.

El 03 de abril de 2008 (semana epidemiológica N. ${ }^{\circ}$ 14), se presentaron tres pacientes febriles, con infección respiratoria alta, caracterizada por malestar general, dolor de garganta y rinorrea. El primer caso se presentó en la Unidad Militar (UM) \# 1, había estado en contacto por dos días con el personal de la UM \# 2. Rápidamente los casos se incrementaron, lo que motivo la intervención conjunta del personal de la JESAL y del MINSA con el apoyo del NMRCD para el estudio del brote.

El objetivo de esta publicación es presentar las características clínico epidemiológicas de los pacientes captados durante este brote de enfermedad respiratoria aguda en una base militar en la ciudad de Trujillo, así como las características genéticas de una región del gen de hemaglutinina del virus de influenza circulante.

\section{EL ESTUDIO}

Población en estudio. Se incluyó a todos los pacientes militares con fiebre y cuadro clínico de enfermedad respiratoria aguda atendidos en el período de estudio.

Definición de caso sospechoso. Pacientes militares pertenecientes a las UM acantonadas en la GUI de Trujillo, que presentaban temperatura mayor o igual de $38^{\circ} \mathrm{C}$, de inicio brusco acompañada de tos o dolor de garganta, que podía o no tener síntomas sistémicos como mialgias, postración, cefalea o malestar general ${ }^{(6)}$ a partir del 3 de abril de 2008.

Definición de caso probable. Todo caso sospechoso con prueba rápida de influenza positiva.

Definición de caso confirmado. El aislamiento viral fue la prueba confirmatoria, razón por la cual se estableció que se obtendría muestra de hisopado faríngeo a todos los casos sospechosos con hasta cinco días de inicio de síntomas.

Recolección de datos. Un equipo del CMM estuvo a cargo del estudio de brote, con el apoyo técnico de la Dirección de Epidemiología de la Gerencia Regional de Salud de La Libertad (GERESA). Todos los datos fueron registrados en una ficha de vigilancia de influenza y otros virus respiratorios utilizada por el NMRCD basada en la ficha propuesta por la DGE. Como parte del trabajo colaborativo con el MINSA, todas las fichas fueron enviadas al establecimiento de salud de referencia para su notificación respectiva a la Dirección de Epidemiología de la GERESA. Se analizaron los resultados consolidando solamente los casos de la unidad militar \#1, debido a que en la unidad militar \#2 solo se identificó el caso índice probable.

Manejo de casos. Identificado el brote, todos los pacientes con síntomas respiratorios fueron aislados en habitaciones no individuales temporalmente acondicionadas para dicho fin sin un patrón específico para la distancia entre cama y cama. Se les administró antipiréticos, antihistamínicos y adecuada hidratación, asimismo, 
se organizó charlas sobre medidas de higiene y aspectos generales de la enfermedad, formas de transmisión, síntomas y signos, en especial, sobre la importancia de cubrirse la boca y nariz al estornudar o toser y el lavado frecuente de manos, a fin de evitar el contagio a otras personas. La Comandancia de la Brigada de Infantería de Trujillo asumió los gastos de los medicamentos.

El tratamiento indicado para los casos fue paracetamol $500 \mathrm{mg}$ una tableta cada seis horas, así como metamizol $1 \mathrm{~g} \mathrm{IM}$, más diclofenaco $75 \mathrm{mg}$ IM si presentaban fiebre mayor o igual a $38,5^{\circ} \mathrm{C}$. Ninguno de los militares recibió vacuna contra la influenza ni como parte de las medidas de control ni como profilaxis.

Análisis de laboratorio. Se obtuvo dos tipos de muestra con hisopo de dacrón, un hisopado nasal para la ejecución de prueba rápida (QUICKVUE Influenza A+B Test Quidel Corporation, USA) y un hisopado de secreción faríngea con el fin de realizar, específicamente, aislamiento viral en aquellos pacientes con hasta cinco días de tiempo de enfermedad. La prueba rápida se procesaba in situ al colocar el hisopo en un tubo con una solución de extracción de antígenos víricos que ante la presencia de virus de influenza A o B, dejaba expuestas las nucleoproteínas víricas. Luego se introducía la tira de prueba y si la muestra tenía antígenos daba una reacción de color entre los 2 y 10 minutos. El resultado de la prueba rápida se brindaba al paciente en el momento de la evaluación.

Las muestras de secreción faríngea fueron colocadas y almacenadas en tubos con medio de transporte Universal Transport Media (UTM) los cuales se congelaron a una temperatura de $-70{ }^{\circ} \mathrm{C}$ y fueron enviadas en en cajas con hielo seco hacia el NMRCD en Lima, Perú.

En Lima, las muestras fueron inoculadas en tres líneas celulares: para el aislamiento del virus de influenza se utilizó células Madin-Darby de riñón canino (MDCK, por sus siglas en inglés), así como células de riñón de mono verde (VERO) y células de riñón de mono rhesus (LLCMK2) para identificar virus sincitial respiratorio (VRS), adenovirus, coxsackie, herpes virus y parainfluenza tipos 1, 2 y 3 . Después de diez días se procedió a la identificación viral por medio de la prueba de inmunofluorescencia directa (IFD) para todos los virus descritos, menos para el enterovirus para el cual se realizó inmunofluorescencia indirecta (IFI).

El ácido ribonucleico (ARN) se aisló del sobrenadante de células MDCK, se usó el QIAamp Viral RNA kit (QIAGEN, Valencia, CA) siguiendo los parámetros dados por el fabricante. Con el ARN obtenido se desarrolló la transcripción reversa y posteriormente la reacción en cadena de la polimerasa (RT-PCR) en un solo paso uti- lizando cebadores de la región de la hemaglutinina para identificar influenza A (subtipo $\mathrm{H} 3$ y H1) el SuperScript III One-Step RT-PCR System kit (Invitrogen, San Diego, CA) La RT-PCR se desarrolló usando cebadores específicos ${ }^{(9)}$ para cada subtipo de influenza A, H1 (H1F-6 y H1R-1193), H3 (H3F-7 y R-1184). Los productos del RTPCR fueron purificados utilizando Centri-Sep Columns (Princeton Separations) y secuenciados utilizando el kit Big Dye Terminator (Applied Biosystems, Foster City, CA) de acuerdo a las instrucciones del fabricante. Las muestras fueron analizadas con el software Sequencer 4.8 (Applied Biosystems, Foster City, CA).

Se seleccionó diez muestras al azar, con cultivo viral positivo para realizar la genotipificación. Las secuencias de nucleótidos fueron analizadas utilizando el programa Sequencer, luego fueron ingresadas en el GenBank para compararlas con los subtipos circulantes de influenza en el ámbito mundial. El análisis filogenético se realizó con el programa MEGA 4.0 utilizando el método de Neighbor-Joining.

Aspectos éticos. El protocolo NMRCD.2002.0019 con el cual se estableció la vigilancia fue aprobado por el Comité de Ética del Centro de Investigación Médica Naval de acuerdo con todas las regulaciones federales que protegen a los sujetos humanos. La intervención se enmarcó dentro del contexto de una investigación de brote según procedimientos establecidos por el Ministerio de Salud. EI NMRCD participó con la autorización de la

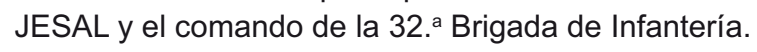

\section{HALLAZGOS}

Del 01 al 08 de abril de 2008 (semanas epidemiológicas N. ${ }^{\circ} 14$ y 15) en el cuartel \# 1 , de un total de 70 militares expuestos, se detectaron 58 (83\%) pacientes con infección respiratoria aguda (Figura 1). Tres de los militares

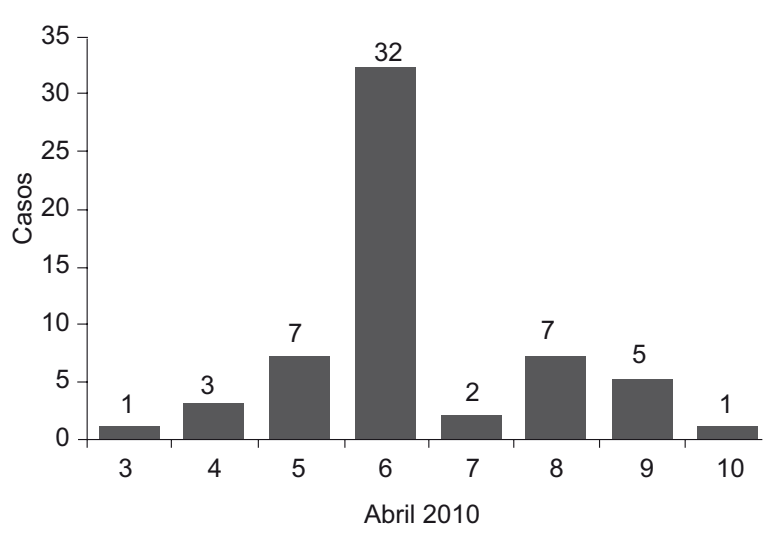

Figura 1. Distribución del número de casos según día de inicio de síntomas. Centro Médico Militar, Trujillo, Perú. 2008. 
Tabla 1. Características de la población militar estudiada. Trujillo Perú, 2008.

\begin{tabular}{lc}
\hline \multicolumn{1}{c}{ Características } & Frecuencia \\
\hline Número de sujetos notificados & $59^{*}$ \\
\hline Número de muestras (enrolados) & 58 \\
\hline Edad media $\pm \mathrm{DE}^{\dagger}$ (años) & $21,5 \pm 8,1$ \\
\hline Mediana [rango] & $19[18-65]$ \\
Tasa de ataque & $82,9(58 / 70)$ \\
Viajes en los últimos 7 días & No reportado \\
Antecedente de vacunación & No reportado \\
Contacto con animales domésticos & No reportado \\
o silvestres & \\
Ingestión previa de medicamentos & No reportado \\
Prueba rápida & 58 \\
$\quad$ Influenza A & 40 \\
Influenza B & 0 \\
Negativo & 18 \\
Cultivo viral & \\
Influenza A & 43 \\
Herpes virus (HSV) & 1 \\
Negativo & 14 \\
\hline
\end{tabular}

*El caso índice probable fue notificado pero no se obtuvo muestra para cultivo viral.

† Desviación estándar

expuestos pertenecían a una unidad diferente que por diversos motivos visitaron la unidad militar afectada y presentaron sintomatología, quedando en aislamiento con todos los afectados. La Tabla 1 resume las características de la población afectada.

La edad promedio de los pacientes fue de $21 \pm 8,1$ años. El grupo etario más afectado fue el de 16 a 20 años con 41 casos, seguido por el grupo de 21 a 25 años con 12 casos. Todos eran de sexo masculino. Solo un caso era de la UM \#2. El tiempo promedio de duración de los síntomas fue de cinco a siete días. No se registró complicaciones ni

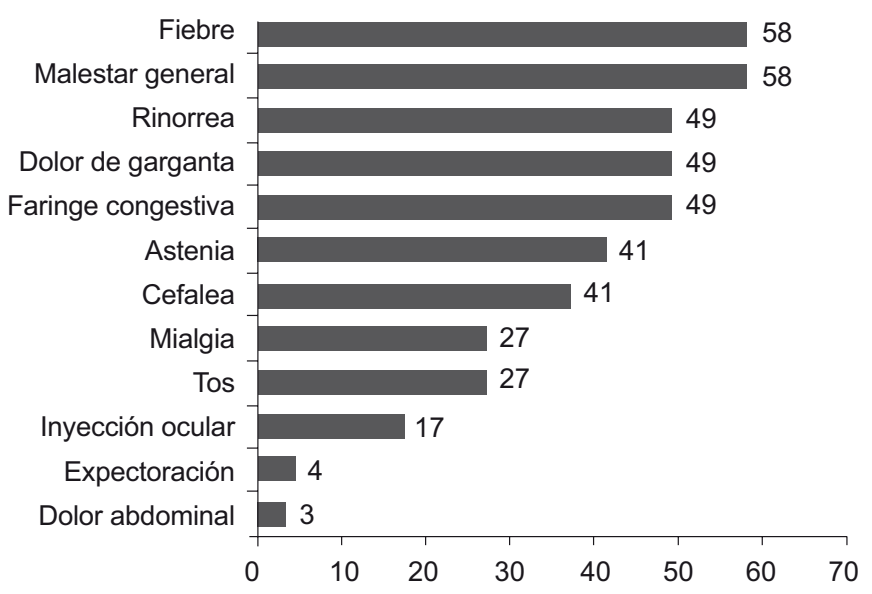

Figura 2. Frecuencia de signos y síntomas presentados en el brote de influenza en población militar, Trujillo, Perú. 2008. defunciones por influenza. Aparte de la fiebre, los síntomas más frecuentes fueron malestar general en todos los casos, en 49 (84\%) pacientes se detectó rinorrea, faringe congestiva y dolor de garganta, solo en $4(6,8 \%)$ hubo expectoración y en 3 (5\%) dolor abdominal (Figura 2).

En 40 (69\%) pacientes la prueba rápida fue positiva para influenza A y en un total de 43 (74\%) militares se aisló influenza A. Asimismo, en la muestra de un paciente se aisló herpes virus. No hubo aislamiento de otros patógenos virales.

Cultivo celular. El cultivo celular de 43 (74\%) muestras fueron positivas a influenza del tipo A. Se genotipificó $10(23 \%)$ de las muestras en las cuales se identificó que la cepa circulante pertenecía al genotipo $A /$ Brisbane/59/07-like ${ }^{(7)}$.

\section{DISCUSIÓN}

En el contexto de una vigilancia centinela establecida por la DGE y el INS, con la participación del NMRCD, se presentó un incremento de casos respiratorios en una unidad militar. La sede militar estaba en pleno proceso de implementación pero fue lo suficientemente hábil para elaborar medidas de contención adecuadas. Cabe resaltar que al contar con pruebas rápidas de influenza, que si bien es cierto no tienen una alta sensibilidad, pueden ser muy útiles en el diagnóstico inicial del brote, evitando altas cifras de morbilidad.

La vigilancia centinela tiene limitaciones claras, especialmente al no poder mostrar tasas de incidencias, pero nos sirve, entre otras cosas, para poder conocer cuál es la circulación viral en un área.

Detectar brotes en sus estadios iniciales permite proponer medidas de control precoces para evitar su propagación, así como plantear investigaciones para determinar factores de riesgo asociados. De aquí la importancia de una consolidación, evaluación y difusión de los datos en forma inmediata a las autoridades locales y los médicos tratantes.

El evento aquí descrito es un brote de influenza tipo A que tuvo una tasa de ataque del $82,9 \%$ (58/70). Los aislamientos de $74 \%$ fueron genéticamente similares con la cepa A H1N1 Brisbane.

Consideramos que el brote empezó en el cuartel, debido a que la unidad estaba de inspección y el personal no había salido durante los últimos cinco días; asimismo, el caso índice probable identificado había estado en la unidad durante los dos últimos días antes de la aparición 
del brote, considerando que la influenza es una enfermedad aguda con un tiempo medio de incubación de dos días y un rango entre uno a cuatro días ${ }^{(10)}$.

Durante el brote, se priorizó el uso de material para toma de muestra en los casos nuevos, lamentablemente no se pudo confirmar el caso porque el paciente ya no estaba dentro de los primeros cinco días para la obtención de muestra para cultivo cuando se tuvo disponibilidad de los medios. Considerando el valor predictivo positivo de la prueba rápida de influenza encontrada en nuestros estudios previos (85\%), entendemos que este paciente tenía alta probabilidad de ser un caso de influenza ${ }^{(7)}$.

El período de incubación de la enfermedad fue corto, puesto que los síntomas se presentaron de forma abrupta, todos los casos atendidos, han estado en su primer o segundo día de inicio de síntomas, algunos casos con cuadros más leves. No se reportaron complicaciones.

Uno de los factores que contribuyen a brotes de influenza, es la permanencia en lugares relativamente cerrados como son las instalaciones militares ${ }^{(11)}$, por ser cuadras en las cuales pernoctan y viven una cantidad grande de efectivos militares, aun considerando que los ambientes son amplios y ventilados tienen las condiciones para la diseminación fácil de algunas infecciones, en especial si se transmiten por vía aérea o aerosoles.

Es importante mencionar que en este brote no se utilizó ningún tipo de vacunas para su control, a pesar que ya fueron utilizadas en brotes en poblaciones militares (11,12); únicamente fueron implementadas medidas de aislamiento del personal para evitar la diseminación del virus, detección y tratamiento precoz de los casos. El efectivo militar quedó inmovilizado en su cuadra evitando el contacto con los otros integrantes de las unidades acantonadas en ese cuartel. Así, la detección precoz de un brote en lugares cerrados como las bases militares permitió actuar de manera inmediata para prevenir su diseminación, iniciando tratamiento precoz y evitando otras complicaciones. A su vez, en un contexto prepandémico sirvió para fortalecer las actividades de vigilancia y control local. Asimismo, sirvió para mostrar que el sistema de vigilancia tiene la capacidad de mostrar qué virus está circulando.

Finalmente, podemos afirmar qué medidas simples tomadas adecuadamente sirvieron efectivamente para el control de este brote. Desde el punto de vista molecular podemos afirmar que solo el genotipo $\mathrm{A} / \mathrm{H} 1 \mathrm{~N} 1$ con similitud genética al linaje A/Brisbane/59/07-like estuvo circulando en este episodio y es el mismo que estuvo circulando en marzo de 2008 en los departamentos de Tumbes y Piura como ya fue reportado en el Perú ${ }^{(7)}$.

\section{AGRADECIMIENTOS}

A la Dra. Julia S. Ampuero Vela por la lectura crítica, revisión y sugerencias al texto. Al personal técnico y de enfermería del Centro Médico Militar de Trujillo que participó en la atención del personal militar afectado y a la Comandancia de la 32. ${ }^{\text {a }}$ Brigada de Infantería por el apoyo técnico y logístico en la solución de esta contingencia. A todos ellos el sincero agradecimiento puesto que se ha mostrado que nuestro objetivo de velar por la salud de nuestra tropa se ha cumplido.

\section{Fuente de Financiamiento}

Este trabajo ha sido financiado por la unidad de trabajo (Work Unit No. $8477058200025 G B$ B0016) y por la Co-

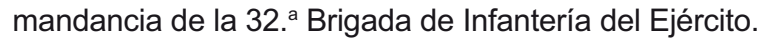

\section{Conflictos de Interés}

Los autores declaran no tener conflictos de interés en la publicación de este artículo.

\section{Disclaimer}

Las opiniones y afirmaciones contenidas aquí son propias de los autores y no deben interpretarse como posición oficial o que reflejan la opinión del Departamento de la Marina o del servicio naval de los Estados Unidos. Copyright. Algunos de los autores de este trabajo son personal que trabaja para el Ministerio de Defensa de los Estados Unidos y este trabajo ha sido preparado como parte de sus funciones oficiales.

\section{REFERENCIAS BIBLIOGRÁFICAS}

1. Liu PY, Wang LC, Lin YH, Tsai CA, Shi ZY. Outbreak of influenza $A$ and $B$ among military recruits: evidence from viral culture and polymerase chain reaction. J Microbiol Immunol Infect. 2009;42:114-21.

2. Kawana A, Naka G, Fujikura Y, Kato Y, Mizuno Y, Kondo T, et al. Spanish influenza in Japanese armed forces, 19181920. Emerg Infect Dis. 2007; 13 (4): 590-593.

3. Sperber SJ, Francis JB. Toxic shock syndrome during an influenza outbreak. JAMA. 1987;257(8):1086-87.

4. Dietzman DE, Schaller JG, Ray CG, Reed ME. Acute myositis associated with influenza B infection. Pediatrics. 1976;57(2):255-58.

5. Molinari NA, Ortega-Sanchez IR, Messonnier ML, Thompson WW, Wortley PM, Weintraub E, et al. The annual impact of seasonal influenza in the US: measuring disease burden and costs. Vaccine. 2007; 25 (27): 5086-96.

6. Perú, Ministerio de Salud. Vigilancia centinela de la influenza y otros virus respiratorios. Directiva $N^{\circ} 057-M I N S A /$ OGE-V01. Lima: MINSA; 2005.

7. Laguna-Torres VA, Gomez J, Ocaña V, Aguilar P, Saldarriaga T, Chávez $\mathrm{E}$, et al. Influenza-like illness sentinel surveillance in Peru. PLoS One. 2009;4(7):e6118. 
8. Saldarriaga T, Laguna-Torres, V, Arrasco J, Guillen L, Águila J, Aguilar P. et al. Características clínicas y moleculares de un brote de influenza en dos bases militares, Tumbes - Perú, 2007. Rev Peru Med Exp Salud Publica. 2008;25(1):35-43.

9. Daum LT, Canas LC, Smith CB, Klimov A, Huff W, Barnes W, et al. Genetic and antigenic analysis of the first A/ New Caledonia/20/99-like H1N1 influenza isolates reported in the Americas. Emerg Infect Dis. 2002;8(4):408-12.

10. Bridges CB, Kuehnert MJ, Hall CB. Transmission of influenza: implications for control in health care settings. Clin Infect Dis. 2003;37(8):1094-101.

11. Balicer RD, Huerta M, Levy Y, Davidovitch N, Grotto I. Influenza outbreak control in confined settings. Emerg Infect Dis. 2005; 11(4): 579-83.
12. Grotto I, Mandel Y, Green MS, Varsano N, Gdalevich M, Ashkenazi I, et al. Influenza vaccine efficacy in young, healthy adults. Clin Infect Dis. 1998;26(4):913-17.

\section{Correspondencia: Edward Chávez}

Dirección: Centro Médico Militar, 32. ${ }^{a}$ Brigada de Infantería, Trujillo Perú

Teléfono: (51) 949012365

Correo electrónico: edwardchavezc@hotmail.com

V. Alberto Laguna Torres

Dirección: Av. Venezuela s/n Hospital Naval. Lima, Perú. Teléfono: (511) 614-4166 anexo 166

Correo electrónico: alberto.laguna@med.navy.mil

Suscríbete en forma electrónica y gratuita a los contenidos de la

Revista Peruana de Medicina Experimental y Salud Pública, ingresa a WWW.ins.gob.pe, selecciona el ícono de la revista y envíanos tus datos.

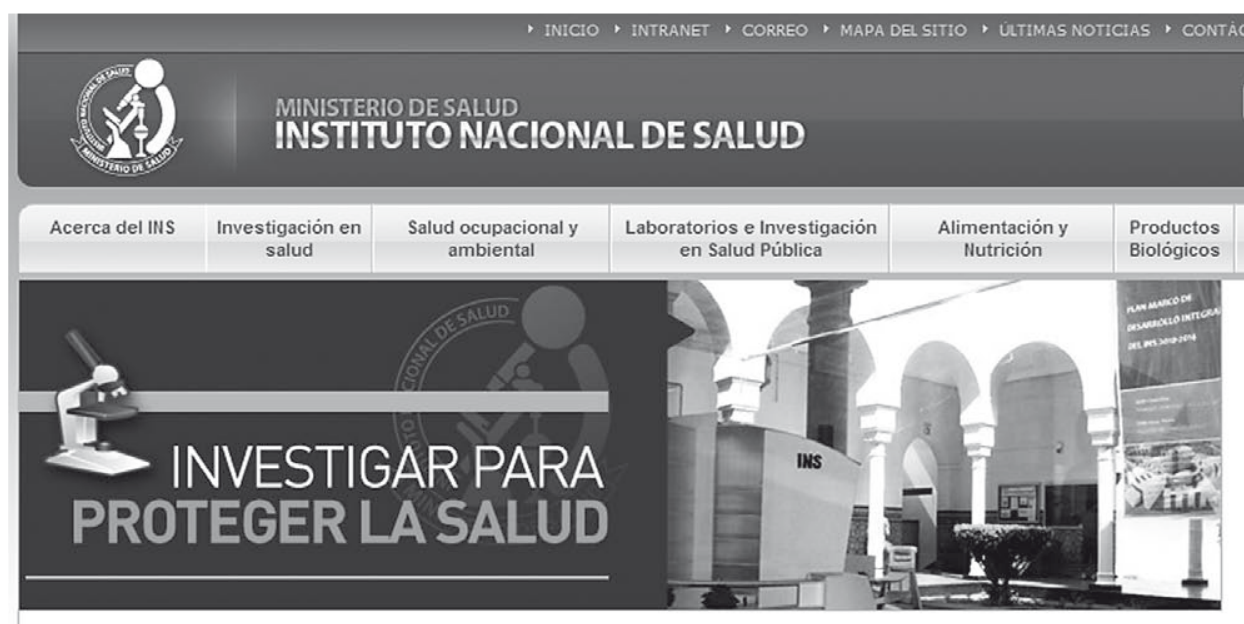

ÚLTIMAS INVESTIGACIONES Y EVIDENCIAS CIENTIFICAS Ver Todas

Programa de Investigación : Reporte de Vigilancia de Hidatidosis en Zonas Endémicas

05-01-2010

Resultados del Programa de Investigación de HIDATIDOSIS. Ver detalle Virológica de Influenza y otros Virus Respiratorios 31-05-2010 Ver archivo Ver detalle

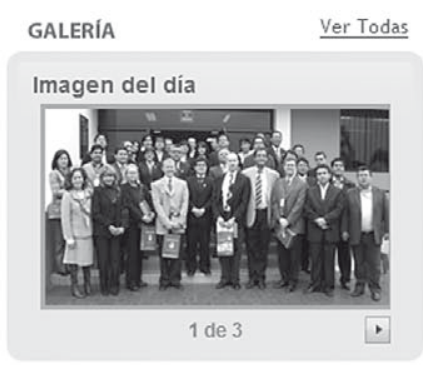

NOTICIAS
Salud Control de Calidad Buscar...

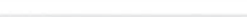

25 de junio del 2010

Agregar a favoritos

2 Enviar a un amigo

N Gestión de calidad

III Transparencia

Directorio Institucional Publicaciones

(2) Revista Peruana de Medicina Experimentair Salud Pública $\underline{\text { Ver más }}$ Centro INVESTIGACION 